\title{
METHODOLOGICAL BASES OF CLASSIFICATION OF SOCIAL RISKS
}

\author{
Svitlana Berezina ${ }^{1}$
}

\begin{abstract}
The purpose of the study is to develop methodological principles of classification of social risks in the context of requirements of social risk management. The risk is considered as possible occurrence of a risk of a negative state of a particular phenomenon or event, undesirable by the object. Social risks are proposed to be all risks arising in the social sphere. When analysing the existing solutions to the problem, classifying social risks according to the requirements of social risk management, the paper uses the following research methods: system approach, analysis and synthesis. The research subject - social risks in the light of their classification by certain characteristic features from the perspective of requirements of social risk management. Analysis of the application of hierarchical and facet methods for the classification of social risks is carried out. The use of a combined approach, i.e. when at some levels of classification risks are classified by using the hierarchical method, and at others - by facet one, is proposed. The necessity and sufficiency of 6 levels of risk division are shown. The 1st level of classification is directed to the division of a set of risks by nature and character of occurrence into macrolevel categories, accordingly, into natural, technogenic, economic, and social. The 2 nd level is classified by factors of risk formation. These are risks of social policy, risks of stochastic nature of the formation, physiological risks, and behavioural risks. The 3rd level of classification - risks that are combined in the following forms by the sphere of activity: risks of reproduction of the population, employment of population, income and expenditure of population, living conditions and housing and utilities, education, healthcare, law enforcement, environment, risks of deteriorating social indicators when compared with other countries in the world. The 4th level of classification - by risk types, and the 5 th - by levels of the hierarchy of public activity. The 1st, 2nd, and 4th levels are classified by the hierarchical method, 3rd and 5th - by facet method. The 6th level is facet with the horizontal distribution of risks into facets by different features. Conclusion. It is substantiated that obtained results arise from the provisions of economic theory and are in agreement with the acting organisational structure of societal life, which will contribute to creating better conditions for managing social risks. Social risk management begins from the definition of type and nature of risk, place and level of its formation, presentation of its determined characteristics. Here a need arises to divide a set of risks based on the defined signs and criteria into separate subsets. That is, a need arises to classify risks into more concrete groups with similar features. Accordingly, risk classification is important and necessary stage of social risk management. In practice, risk classification is carried out, as a rule, by using facet method when each facet includes an aggregate of risks with homogeneous values of this classification feature. Facet classification is single-level, that is, it does not stipulate for further division of risks into more detailed groups, however, the need for vertical hierarchical multilevel specification arises. The analysis shows that multilevel combined classification system when hierarchical method alternates with facet one satisfies the requirements of social risk management.
\end{abstract}

Key words: social risks, social risk management, methods of classification, social risk classification by sphere of activity, classification by levels of hierarchy of society.

JEL Classification: J11, J18, G17

\section{Introduction}

In the process of activity, people face a number of various risks. Studying theoretical issues related to the management of risks, including social ones, is a relevant scientific and practical task. Along with this, in addition to the definition of nature, main characteristics and functions of risks, risk classification and analysis of the causes of their formation are of great importance. The research object is social risks in the light of their classification by certain characteristic features from the

\footnotetext{
Corresponding author:

${ }^{1}$ Taras Shevchenko National University of Kyiv, Ukraine.

E-mail: svieta_berezina@ukr.net

ORCID: http://orcid.org/0000-0002-9737-0651
} 
perspective of requirements of social risk management. The purpose of the study - to develop methodological principles of classification of social risks in the context of requirements of social risk management. The following research methods are used in the paper: system approach (for building the author's approach to the classification of risks as a system of interrelated elements), analysis and synthesis (when analysing the existing solutions to the problem, classifying social risks according to the requirements of social risk management).

Studies on the issue of social risks have been taking place for several centuries. Their appearance is associated with various factors: aggravation of capitalist competition and the spread of gambling, in particular, stock market games etc. However, these studies were able to obtain real scientific foundation only after philosophical works by G.W.F. Hegel (1770-1831) and sociology created by A. Comte (1798-1857) and E. Durkheim (1858-1917). They have developed a special view of society as an emergent system, i.e. a structure that has its own characteristic features different from features of subjects of society. A lot of works of foreign scholars are devoted to this research area: J. Galbraith, R. Holzmann, A. Giddens, M. Douglas, A. Mozgovaya, N. Luhmann, B. Norman, O. Renn, P. Slovic, O. Yanitskii, and others. They reveal the concept of risks and classify them according to various features and types, consider the issue of sources of "social risk" as a special variety.

In Ukraine, there are also many works devoted to the research topic, among which, first of all, we should note works of members of Ptoukha Institute for Demography and Social Studies of the NAS of Ukraine conducted under the guidance of Academician E. M. Libanova (Libanova, 2014, 2015; Nadraga, 2015). These works formulated the most weighed definition of social risks as threats that emerge and are manifested within the social sphere of society, have negative social consequences, influence the vital activity of individuals, social groups, and society as a whole. There are also presented some approaches to the classification of risks.

Among the developments of other scholars, one should distinguish works by (Libanova, Gorbulin, 2015; Vlasyuk, 2015; Donets, 2014; Shopenko, 2011) and many others. They study both general scientific topics and applied issues of risk classification. Other works are of general-theoretical direction, for example, the paper by (Beck, 2010) where the author proposes to consider all the sociology and economy through the lens of riskiness, or the work by (Topyshko, 2017) that offers to withdraw from strict mathematical methods and assess risks on the basis of the so-called theory of fuzzy sets, and so on. Now, studies are taking place by using methodological tools of such disciplines as: system theory; probability theory; mathematical theory of games; social theory; economic theory; prognostics; riskology, etc. Many educational publications are devoted to separate issues of determining the essence and directions of classification of social risks. As a rule, simplified types of risk classification by some characteristic features are used there. In general, it can be stated that although a lot of publications and research studies are devoted to the problem of risk classification, such its aspects as a justification of approaches to the classification of social risks according to the requirements of social risk management remain relevant and extremely important for further research.

\section{Essence and problems of classification of social risks}

Risk as a complex phenomenon has many characteristics. More often it is defined as the danger of loss of resources or lack of income compared with the option designed for the rational use of resources. The risk is also defined as a conscious possibility of the risk of unexpected losses of expected profits, property, money in relation to accidental changes in the conditions of economic activity, adverse circumstances (Libanova, Gorbulin, 2015). The complexity and diversity predetermine the possibility of existing of several definitions of risk concept from different points of view depending on the research goals. Nevertheless, risks have their own features (all of them presuppose the danger of loss, come in the form of natural phenomena or events in society, etc.), which gives the author the possibility to give their unambiguous general definition in the form: risks - phenomena or events, the probable or foreseen occurrence of which will lead or may lead to negative consequences. Such a definition is most general and to a great degree corresponds to the concept of risk management, which will contribute to more effective management of risks. The most widespread category of risks is social risks that affect the level and quality of life of the population. Their concept can be formulated in the following form: social risks are risks that appear in the social sphere of society. Or a more complete definition - social risks are phenomena or events that appear in the social sphere of society and the probable or foreseen occurrence of which will lead or may lead to negative consequences.

In the majority of works, the following essential features of social risks are distinguished:

- differentiation (social risks are assumed by the individual, separate segments of the population or society as a whole);

- the probability of occurrence;

- the inevitability of losses (social risks initiate problems that cannot be completely excluded, solved but only minimised, managed with one or another degree of effectiveness);

- social responsibility of all social and professional groups of society (social risk management is successful only along with effective partnership, interested cooperation of all the participants of this process). 
According to the results of conducted analysis on nature of occurrence and manifestation, the following characteristic features of social risks also can be added: a) social risks arise in the social sphere. Natural, technological, and economic risks generally affect the state (budget) and particularly individuals as the loss of property, health etc.;

b) formation and level of influence of social risks to a great extent depend on the acting system of social policy and manner of implementation of its main categories;

c) social risks have risk objects and subjects;

d) risks of social policy for risk object may be both negative and positive (almost all researchers, as a rule, consider negative results of risks only);

e) risks of social policy and behavioural risks provide for several options for making a decision;

f) in case of failure of risk option realisation, risk object suffers additional losses.

There are a lot of approaches to the classification of risks differed both by classification features and by aims and objectives of the study. So, for example, by the area of formation (natural, technogenic, economic, and general civil), by the scale of action (universal and special), from the perspective of risk object (by its manifestation for separate population groups), depending on the probability of occurrence and cyclical nature of human life (planned, predicted, unexpected). In addition to such a classification, there are many other its types, which are systematised in Table 1.

Such a division is acceptable only for preliminary analysis. In the event of the necessity of in-depth analysis, its disadvantages are:
- chaotic determination of classification features in the absence of a unified approach;

- different notions of the term of social risks when it means not all risks arising in the social sphere but only those covered by social protection;

- most of the classifications are designed to divide economic risks by reference to the general category "socio-economic risks" that do not always correspond to the requirements and essence of social risks;

- existing classifications do not correspond to the requirements of social risk management in terms of dividing risks into similar groups in order to determine management methods.

Accordingly, for a more detailed, essential analysis and development of measures of management of risk management tools, it is appropriate to investigate approaches to the classification from the perspective of economic theory, which considers classification as a system of distribution of objects (goods, phenomena, processes, concepts) into classes according to certain feature and research objective.

\section{Methodological approaches to the classification of social risks}

Hierarchical, facet, and descriptive methods of object classification are distinguished in economic theory. The hierarchical classification system is built as follows: the initial set of elements is the 0 level and is divided according to the selected classification feature into classes (groups) that form the 1st level; each class of level 1 in accordance with its characteristic classification features is divided into subclasses that form the 2 nd level and so on.

Table 1

Classification of social risks by various features

\begin{tabular}{|l|l|}
\hline \multicolumn{1}{|c|}{ Classification feature } & \multicolumn{1}{c|}{ Division of risks into classification groups } \\
\hline By nature of causes & Intentional, unintentional \\
\hline By the time of formation & Retrospective, current, perspective \\
\hline By factors of formation & Political, economic \\
\hline By place of formation & External, internal \\
\hline By consequences & Pure, speculative \\
\hline By area of formation (nature of activity) & $\begin{array}{l}\text { Business risks: production, commercial, financial, insurance risks; } \\
\text { and also occupational, investment, transport and other risks }\end{array}$ \\
\hline By hazard type & Technogenic, natural, and mixed \\
\hline By level of formation & Macro, meso, and micro level \\
\hline By degree of definiteness & Known, foreseeable, unforeseeable \\
\hline By stages of formation & Project, planned, actual \\
\hline By degree of reasonableness & Reasonable, unreasonable \\
\hline Be degree of potential losses & Tolerable, critical, catastrophic \\
\hline By the scale of consequences & Global, regional, local \\
\hline Depending on the form of impact on society & Direct, indirect \\
\hline $\begin{array}{l}\text { Depending on the probability of occurrence and cyclical nature of } \\
\text { human life }\end{array}$ & Planned, predicted, unexpected \\
\hline By possibility of prediction & Foreseeable, unforeseeable \\
\hline By duration & Short-term, long-term \\
\hline
\end{tabular}

Source: systematised by the author 
The facet classification system allows selecting classification features independently as from each other, so from the semantic content of the classified object. Classification features are called facets. Each facet includes a set of homogeneous values of this classification feature. The classification procedure consists in assigning to each object the corresponding values from the facets. In this case, not all facets can be used, but only some that are characteristic of this feature.

The descriptive classification system is designed for the organisation of information search, maintenance of thesauruses (vocabularies). It is especially widely used in the library search system. The essence of this classification method is as follows:

a set of key words or phrases describing a particular subject area or a set of homogeneous objects is selected. And among the keywords can be synonyms;

the selected keywords and phrases undergo normalisation, that is, from the set of synonyms one or several most used ones are selected;

a dictionary of descriptors is created, that is, a dictionary of key words and phrases selected as a result of the normalisation procedure.

The existing classifications of social risks are usually limited to the facet method. In this case, the classification is carried out on the basis of only individual, arbitrarily selected and clearly visible properties of objects. Hierarchical classification is based on the division of risks into individual characteristic risk groups, followed by their division into types with more detailed features, i.e. groups combine specific types of risks by the essential feature of this group. Unlike the facet, it is based on the full understanding of the essence of the objects being classified, and is not just identifying, but identifying-explanatory. It explains the common characteristics of the classification groups and the nature of the relationship between them. The detailing can be multilevel, in the form of a "tree of signs", which are united into a single system. Fig. 1 shows the classification scheme by hierarchical and facet methods. As an example, there is shown the division of the set of risks into subclasses based on the category into natural and others (it can be technogenic, economic, etc.). Further, the natural risks are divided into smaller groups by their feature (for example, by the factor of occurrence), and so on.

The same set of risks can be classified by a facet method into two or more types, for example, by scale of consequences into global, regional, and local. Or the same set can be divided by another sign. Depending on the purpose of the classification, the researcher or the manager chooses the appropriate method.

\section{Social risk classification according to requirements of social risk management}

The main requirement of social risk management in relation to the classification of social risks is their detailing to a level that would provide the possibility of its unambiguous definition for the analysis and selection of the model of risk management. The general scheme of the proposed combined classification of social risks is shown in Figure 2.

\section{Social risk classification by categories of the formation}

Although all types of risks are diverse, by a set of features they can be grouped into macro categories. The categories should be understood as grouping at the macro level of risks by essence, factors, nature of the occurrence, etc. In literary sources, the following categories of risks are usually distinguished: natural, technogenic, domestic, socio-political, technical, economic, climatic, environmental, political, socioeconomic, etc.

Almost all lists include the category of natural risks associated with natural phenomena. Sometimes the climatic risks are isolated, although they are also natural, and therefore it is not meaningful at the macro level to allocate climatic phenomena as a separate category. Technogenic and technical risks have uniform factors of the formation. In addition, they are prevented by similar methods. Accordingly, it is advisable to combine them into one category - technological risks. Socio-political,

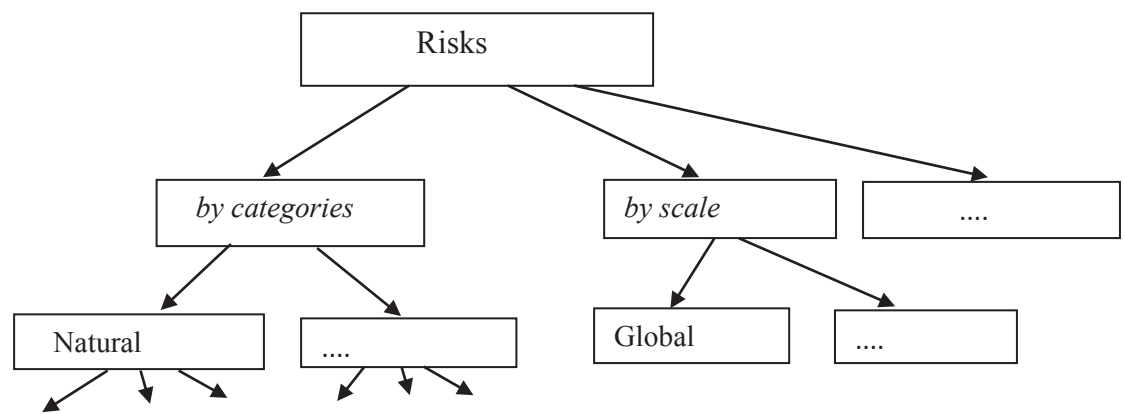

Figure 1. Scheme of risk classification by hierarchical and facet methods 


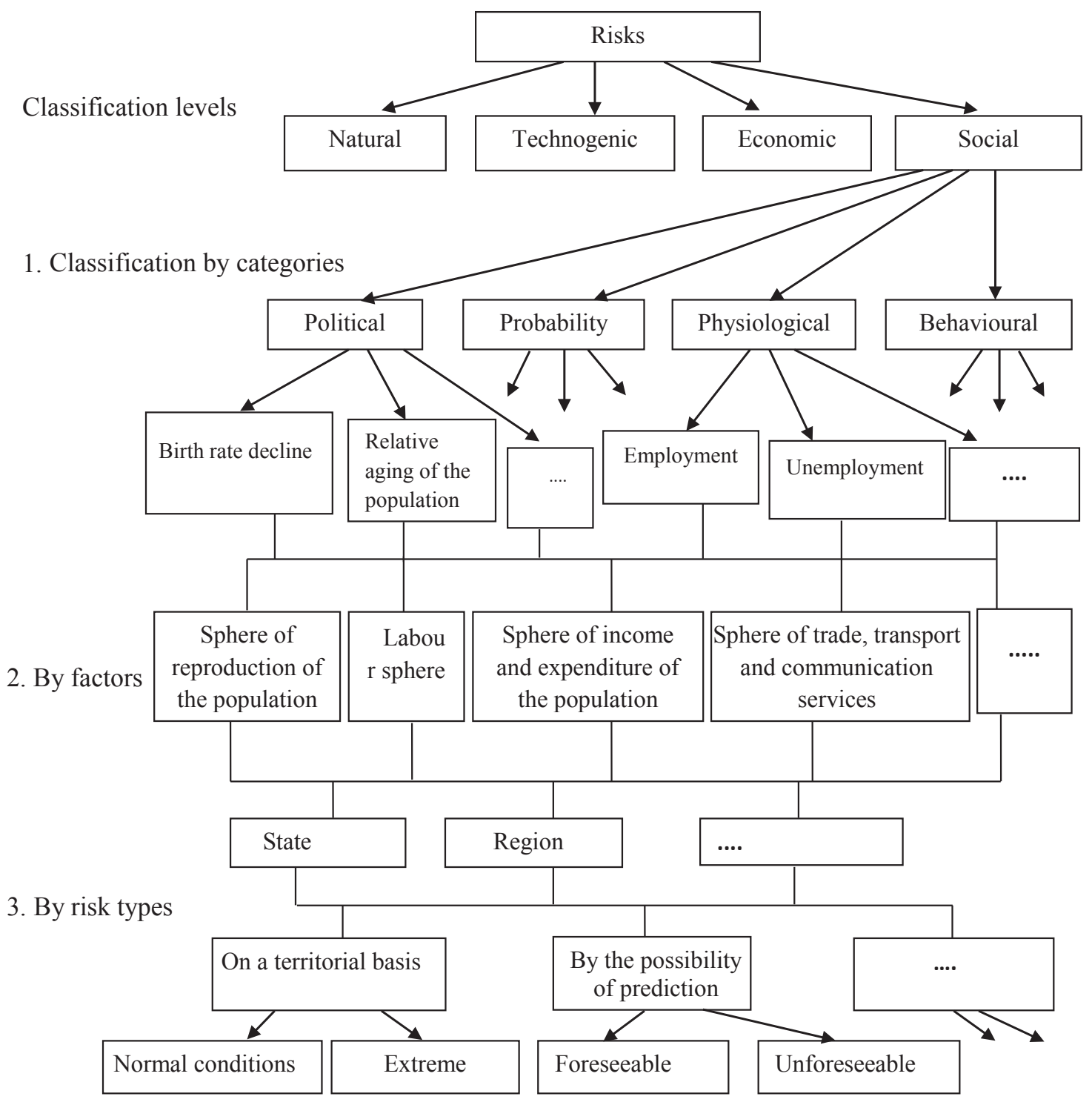

Figure 2. Scheme of combined classification of social risks

Source: developed by the author

domestic, and socio-economic types of risks cover the risks arising in the social sphere of life of society and in the production of goods and services. They are distinguished both by the sphere and the causes and factors of origin, and the feasibility of their independent research is not in doubt. That is, in the list, there should be separate categories - economic risks and social ones. Political risks are the risks generated by the socio-economic policy. It is quite clearly divided into economic and social policies. Accordingly, the risks of socio-economic policy should be divided into economic and social ones and added to the categories of economic and social risks respectively, the more so they differ in methods of prevention or minimization. The analysis conducted shows that all risks by nature, causes, character, and factors of their occurrence should be divided into natural, technological, economic, and social.

\section{Social risk classification by factors of the formation}

The analysis shows that on the basis of the probability of occurrence, sources of origin, and nature of the action, social risks should be classified into the following groups: social policy risks, risks of probability type, physiological risks, and behavioural risks. The classification of risks by categories, factors of formation, and types of risks is given in Table 2 .

Risks of social policy are related to risk decisions of subjects of social policy. These are risks arising in the sphere of services (education, culture, healthcare, public utilities, transport and communication, etc.), demographic and social risks (many children, single-parent family, orphanhood), environmental risks, etc. 
Vol. 4, No. 5, 2018

Table 2

Types of risks by categories and factors of the formation

\begin{tabular}{|l|l|l|}
\hline Category of risks & \multicolumn{1}{|c|}{ Causes of risks } & \multicolumn{1}{c|}{ Types of risks } \\
\hline \multirow{2}{*}{ Natural risks } & $\begin{array}{l}\text { Natural and climatic } \\
\text { phenomena }\end{array}$ & $\begin{array}{l}\text { earthquakes; cyclones; hurricanes; floods; tornadoes; landslides; climate change; } \\
\text { volcanic eruptions; soil erosion; drought; fire, epidemics, etc. }\end{array}$ \\
\hline \multirow{2}{*}{$\begin{array}{l}\text { risks } \\
\text { Economic risks }\end{array}$} & $\begin{array}{l}\text { Accidents, service } \\
\text { deficiencies, errors }\end{array}$ & $\begin{array}{l}\text { transport accidents and catastrophes; accidents at NPPs and TPPs; accidents at chemical } \\
\text { combines; accidents in gas and water supply systems; technogenic pollution of the } \\
\text { environment; design errors; errors in the manufacture of objects; false actions of the } \\
\text { personnel; poor service; low-quality repair; physical wear of equipment, etc. }\end{array}$ \\
\hline \multirow{5}{*}{ Social risks } & Social policy of society & $\begin{array}{l}\text { production risks; transport risks; commercial risks; trading risks; financial risks; risks of } \\
\text { inflation and deflation; currency risks; investment risks; liquidity risks; business risks, etc. }\end{array}$ \\
\cline { 2 - 3 } & Security policy & risks of population reproduction; unemployment risks; risks in the field of social services, etc. \\
\cline { 2 - 3 } & Physiological phenomena & temporary or permanent loss of labour capacity; labour injury; loss of a breadwinner, etc. \\
\cline { 2 - 3 } & $\begin{array}{l}\text { The behaviour of an } \\
\text { individual, group of persons }\end{array}$ & $\begin{array}{l}\text { behavioural risks of individuals, groups, associations of persons; alcoholism; narcotic } \\
\text { addiction; corruption; theft; street crime; poverty; mass protests, etc. }\end{array}$ \\
\hline
\end{tabular}

Source: developed by the author

Security policy risks - risks that occur accidentally in the social sphere as a result of non-compliance with labour protection requirements or violations of established safety rules (labour injury, temporary or permanent disability, occupational disease, etc.).

Physiological risks are risks, the causes of which are physiological reactions or properties of an organism of a particular person (birth, pregnancy and childbirth, old age, death).

Behavioural risks - risks, the causes of which are decisions and actions of specific people acting as independent persons. They can be both motivated and non-motivated decisions of individuals or groups of individuals. These include alcoholism, drug addiction, corruption, crime, mass protests, etc.

The presented division of risks meets the requirements of risk management in terms of determining the methods of risk management that can largely reduce their consequences.

\section{Classification of social risks by types}

Thislevelis classified bythehierarchicalmethod. It provides for the division of each group of risks, which is determined by factors of formation, into separate risks included in this group. So, for example, in the group of physiological risks, there are risks of old age, death, etc. The logic of interaction and interrelation of the main categories of social policy shows that the basis for defining the spheres of social risk formation should be the signs of the corresponding spheres of social activity, that is, the part of an economic activity that serves the specific social needs of society.

List of spheres of activities is widely used in modern economics. It is, for example, the classification of economic activities (KVED 2010), chapters of statistical reporting (annuals of State Statistics Service of Ukraine) and so on. For conditions of social risk management, it is appropriate to take the division of the social part of annuals of State Statistics Service of Ukraine (for example, Ukraine in Figures 2017) into chapters called "Population", "Employment", "Income and expenses of the population" etc. as the basis of such list of spheres. Clarifying a little the name and highlighting separately the sphere "Social Assistance", social risks in the context of risk management should be divided into the following spheres of social activity:

1) sphere of reproduction of the population;

2) labour sphere;

3) sphere of income and expenditure of the population;

4) sphere of trade, transport and communication services;

5) sphere of housing conditions and utilities;

6) education sphere;

7) sphere of healthcare;

8) sphere of law enforcement;

9) sphere of ecology;

10) sphere of the universe (comparison with countries of the world).

Somewhat unusual in this classification is the allocation of the sphere of the universe. However, in conditions of growing globalization of the world, it is extremely necessary to compare the indicators of the state and dynamics of our state with the indicators of other countries. Such a comparison not only gives an idea of the current state of society but also directs development to use the experience of other countries. This level of classification is facet.

Social risks arise and are implemented at different levels of social activity: state, regional, local, etc. All levels of social activity and, accordingly, risks appearing on them, are in continuous interaction, are interdependent, and make up a single system. Nationwide social policy is implemented at the macro level and provides for the choice of social priorities, directions of the government and other subjects of social activity, targeted promotion of certain spheres, implementation of social and environmental programs, etc. At the regional level, there is a social activity, which is an integral part of the policy of socio-economic development of the state. Here are solved regional problems related to the development of 
the society in the region. It is obvious that making risky decisions both at the state and regional levels requires not only prior attention but also the preparation of measures to prevent the occurrence of negative situations.

Local self-government bodies are now dealing with a significant part of the issues of education, healthcare, culture, housing and communal services, consumer services, etc. It includes support for the livelihoods of the weak members of society - the disabled, the elderly, single, displaced persons, etc. Naturally, there may be risks at this level too, so anti-risk measures to overcome their consequences should be foreseen.

As a rule, researchers and practitioners in their works are limited with three hierarchical levels of occurrence and formation of social risks: state, regional, and municipal (local). However, it should be noted that in addition to the listed ones, risks also occur at the level of corporations, various associations (it seems fair to say, at the level of different groups), at the level of particular individuals. Besides interstate levels of occurrence of social risks, in recent years, the external (world) level, where an intergovernmental social policy is formed and where appropriate risks arise, becomes more and more important. That is, the three-level system of hierarchy of occurrence of social risks has turned into a multilevel system. In this case, the list of hierarchical levels of social risks' formation should include:
1. State level.
2. Regional.
3. Municipal.
4. Group.
5. Individual.
6. Global risks (interstate).

In addition to 5 considered levels of classification, the need to divide risks according to other features may arise in practice. For example, the researcher or manager needs to identify risks by place or time of occurrence. In such a case, the 6th level of classification can be used where necessary features can be added in facet form. So, Figure 2 shows additional types of classification on a territorial basis and on the possibility of predicting the occurrence of risks.

Territorial risks constitute a special group. They concern the population living and working in usual or extreme, unfavourable natural and climatic conditions (northern territories, mountainous, arid areas etc.). Their activity is carried out taking into account features of territorial risks. This relates to the age of retirement, labour experience, insurance premiums, and the like.

According to the possibility of prediction, there are two groups of factors of social risk: foreseeable (actions that can be expected, evaluated, they are sufficiently studied by science, are subject to management) and unforeseeable (it is not possible to mark them on an a priori stage of a risk analysis, some may arise for the first time; this group of risks is most difficult to manage).

Risks of the first group can be felt, predicted, and marked for the future by studying, analysing the current situation, historical factors, as well as other indicators that may be involved in the field of social activity. Unforeseen risks are not comparable. It is impossible to determine the time and probability of their active development and occurrence based on historical and other analyses.

Subjective and object risks are also distinguished. Subjective risks are the risks that arise in the decisionmaking process by the subjects of power. Object risks arise as a result of decision-making by risk objects (for example, an individual's decision to play casinos, etc.).

By the way, in the scientific literature, one can find classification of the segregation of residents by income, which expresses the probability of occurrence of risks of a certain level (Giddens): beggarly - $10.7 \%$; poor $-13.7 \%$; proto-middle $-46.7 \%$; middle $-20 \%$; wealthy $-9 \%$.

Although classifications of the 6th level characterise risks only from separate perspectives, along with previous types of risk division they make good sense for a more complete identification of risks.

In conclusion, it can be argued that the proposed approaches to the classification of social risks more completely reflect the essence of this complex concept and will contribute to a better use of risk management methods in the process of social risk management.

\section{Conclusions}

1. Social risk management begins from the definition of type and nature of risk, place and level of its formation, presentation of its determined characteristics. Here a need arises to divide a set of risks based on the defined signs and criteria into separate subsets. That is, a need arises to classify risks into more concrete groups with similar features. Accordingly, risk classification is important and necessary stage of social risk management.

2. In practice, risk classification is carried out, as a rule, by using facet method when each facet includes an aggregate of risks with homogeneous values of this classification feature. The classification procedure consists in assigning to each risk the corresponding values from the facets. Facet classification is single-level, i.e., it does not stipulate for further division of risks into more detailed groups. However, in the process of social risks management, the need for risk division into separate groups arises followed by their division into groups with more detailed features. That is, the need for vertical hierarchical multilevel specification arises. The analysis shows that multilevel combined classification system when hierarchical method alternates with facet one satisfies the requirements of social risk management.

3. Study of the structure of social risk classification system showed the necessity and sufficiency of 6 levels of risk division. The 1st level of classification is directed to the division of a set of risks by nature and character of occurrence into macrolevel categories, accordingly, into natural, technogenic, economic, and social. The 2nd level is classified by factors of risk formation. The 3rd - by spheres of activity, the 4th - by risk types, and the 5th - 
by the levels of the hierarchy of society. The 1st, 2 nd, and 4th levels are classified by the hierarchical method, 3rd and 5 th - by facet method. The 6th level is facet with the horizontal distribution of risks into facets by different features. The latter are determined by researchers or managers depending on the objectives to be achieved.

4. The expediency of social risk classification by spheres and hierarchical levels of social activity is explained by the need to have risk characterisation from this perspective. Classification by spheres of activity indicates not only the place of risk formation but also the subject of responsibility, the state authority in the sphere of which there is a danger. Information on the level of the hierarchical structure of public life gives the specialists of risk management an insight into choosing a model to prevent its impact on the course of social activity.

\section{References:}

Antonova, N. (2016). Risks: classification and management methods within the framework of due diligence. Audit statements, vol. 7 .

Alwang, J., Siegel, P., Jorgensen, S. (2001). Assessing vulnerability: a view from different disciplines, social protection discussion. Paper No. 0115, Washington, D.C. (The World Bank).

Beck, U. (2010). World at Risk. Cambridge: Polity Press.

Giddens, A. Destiny, risk and security. Retrieved from: http://www.hse.ru/data/417/313/1234/5_2_1Gidd.pdf

Galbraith, J. K. (1967). The new industry state. Boston, MA: Houghton Mifflin.

Holzmann, R., Jorgensen, S. (1999). Social protection as social risk management: conceptual underpinnings for the social protection sector strategy paper. Social Protection Discussion Paper. Vol. 9904. The World Bank (Washington, D.C.).

Holzmann, R. (2001). Social risk management: a new conceptual framework for social protection, and beyond, international tax and public finance, 8(4), 529-556.

Donets, L. Rationale for business decisions and risk assessment. Retrieved from: http://westudents.com.ua/ glavy/22688-41-rizik-yak-ekonomchna-kategorya.html

Douglas, M. Risk and culture. An essay on selection of technological and environmental dangers. Retrieved from: http://bookfi.org/book/1364613

Classification of types of risk. Retrieved from: http://stud.com.ua/28347/bzhd/klasifikatsiya_vidiv_riziku

Classification and coding of information. Retrieved from: https://studopedia.org/4-50335.html

Classification of social risks. Retrieved from: https://studme.org/72899/strahovoe_delo/klassifikatsiya_sotsialnyh_riskov Libanova, E. (2014). Demographic shifts in the context of social development. Demography and social economy, $1(21), 9-23$.

Luhmann, N. (2009). Introduction to the system theory. Niklas Luhmann; ed. Dirk Becker. Logos.

Libanova, E. M. (2015). Human development in Ukraine. Modernization of social policy: regional aspect (collective monograph). National Academy of Sciences of Ukraine.

Mozgovaya, A. (2001). Sociology of risk: possibilities of synthesis of theory and empirical knowledge. Risk in the social space. Publishing House of the Institute of Sociology, Russian Academy of Sciences.

Nadraga, V. (2015). Social risks: essence, analysis, possibilities of influence. Monographs. National Academy of Sciences of Ukraine.

Novikova, O. (2016). Assessment of social risks in the regions of Ukraine as the basis for making management decisions on their overcoming. Retrieved from: http://old.niss.gov.ua

Norman, B., Brierley, P., Gibbard, P., Mason, A., Meldrum, A. (2009). Risk-based methodology for payment systems oversight. Financial stability paper, no. 6, August, Bank of England.

Libanova, E., Gorbulin, V., Pirozhkov, S. (2015). Policy of integration of Ukrainian society in the context of the challenges and threats of events in the Donbass (national report). NAS of Ukraine.

Renn, O. (1992). The social arena concept of risk debates. S. Krimsky and D. Golding (eds.): Social theories of risk. Westport, CT (Praeger).

Shopenko, A. (2011). Social risks of a transitive society. Abstract of thesis on the application Doctors of Sociological Sciences. St. Petersburg State University of Engineering and Economics.

Social risk: types and features. Retrieved from: https://businessman.ru/socialnyj-risk-vidy-i-osobennosti.html

Social Risks: Concept and Classification. Retrieved from: http://mestiere.ru/02/25/socaln-riziki-ponyattya-ta-klasifkacya/ Social Risks. Retrieved from: http://www.risk24.ru/sozialriski.htm

Slovic, P. (2000). The perception of risk. London: Earthscan Publications.

Social risk groups. Retrieved from: http://za-strahovanie.ru/socialnoe-strahovanie/gruppy-socialnyh-riskov.html Topyshko, N. (2017). Social risks and the problem of assessing the level of social protection of the population on the basis of the theory of fuzzy sets. Ostrog Academy.

Yanitsky, O. (1998). Russia: risks and dangers of a "transitional" society: collection of articles. Publishing House of the Institute of Sociology, Russian Academy of Sciences.

Vlasyuk, O. (2015). Through decentralization: challenges, risks and priorities for reforming regional development in Ukraine. Regional economy, 1, 5-18. 